\title{
Not the percentage but the cash
}

How much should a nation spend on research and development? Advanced industrial countries generally devote between one and two per cent of their gross domestic product to $\mathbf{R} \& \mathbf{D}$; usually somewhat more than half of the figure will come from government sources, the rest from private investment. Recent OECD figures (OECD Observer No. 97) show that Britain, devoting $2.1 \%$ of its GDP to $R \& D$, still seems satisfyingly committed to science and technology. The reality is somewhat different.

Britain's GDP is (on a per capita basis) little more than half that of many other industrial nations. So if we ask how much money per capita is spent on $R \& D$, Britain's position looks decidedly less distinguished. Whilst the US spends \$200 per capita annually, Germany \$176, Sweden $\$ 171$, the Netherlands \$146, France \$130 and Japan \$103, Britain only manages $\$ 92$. Comparisons look even less happy when an allowance is made for defence $R \& D$ in which the United Kingdom is a heavier spender than almost any other nation. The conclusion has to be that in civil
R \& D expenditure the UK is quietly losing touch with the rest of the industrialised world; not through any visible lack of enthusiasm for science and technology but simply through lack of resources.

Talks of cuts in public expenditure are very much in the air at present as a new Conservative government tries to live up to its election pledge of tax reductions. On the other hand, the Advisory Board for the Research Councils recently made a strong plea for $4 \%$ real growth in science expenditure in the coming years. The many government departments with significant commitment to $R$ \& $D$ will find it easiest to go for a middle path-no real growth. But in another ten years our relative scientific position will then be much worse and scientists will be taking every opportunity to emigrate.

There is no guarantee that a stronger commitment to science and technology will boost the economy-but there hardly seems any doubt that support which is relatively weaker on an international basis will do permanent harm to the nation.

\section{More on your fuel bill}

THE winter in Britain is now over. Any further freak snow-storms, freezes, high winds and flooding should be attributed to next winter; this past winter, by general consensus a miserable one, cannot be blamed indefinitely. There is one final reckoning, however: the last quarter's gas and electricity bills sitting unwanted on doormats around the country.

These bills, everyone must know, are produced by computer. How else would we have a line reading "VAT at $0 \%$ on $£ 72.18=£ 0.00^{\circ}$ or a 52 digit code number sternly marked 'for machine use only'? But what is surprising is not what the computer does to embellish these straightforward demands for money-it is what it leaves out.

Every organisation devoted to the selling of energy is at least nominally also interested in conserving the stuff. Conservation, however, is not just a question of doubleglazing and thick sweaters; it is, or at least it should be, yet another part of that monster of the 1970s-the information industry.

The most valuable piece of information that any energy consumer can have at present is how conservation measures have cut down fuel bills. Did recently installed insulation in the attic have any perceptible effect on the use of fuel? If so, that little bit of information, passed round from person to person, is a much greater incentive to others to invest in conservation measures than is any advertisement proclaiming the merits of insulation. If on the other hand fuel is not conserved thereby, then the consumer should equally be alerted that all is not well.

Presumably within the computers of the utilities there is information on each consumer's energy usage over a period of many years. This by itself would not be adequate to allow for weather fluctuations. But someone, somewhere must be collecting rudimentary data on how cold it issuch as the simple but valuable 'degree-days' measure widely publicised in the United States. It is surely not beyond the wit of the energy utilities to provide a line on each bill giving, say, the number of units consumed per degree-day for the quarter in question-and corresponding figures for the past five years.

No doubt there can be endless discussion about the merits of various units, the possibility that consumers will misinterpret the figures, the fraction of fuel that is used for heating and so on. But anything would be better than today's total lack of information. And there is room on the bill-that line about $0 \times £ 72.18=0$ could go for a start. 